\title{
Knowledge, Attitude and Practice of Doctors Regarding Perioperative Tobacco Smoking Intervention in Surgical Based Discipline in IIUM Medical Centre.
}

Suhaila Binti Nanyan ${ }^{1}$, Tengku Syaifa Izzura Binti Tengku Shaiful Bahril ${ }^{2}$, Amiratul Athirah Binti Mohd Ikhsan², Nor Hazira Binti Ismail ${ }^{2}$

${ }^{1}$ Department of Anaesthesiology and Intensive Care, Kulliyyah of Medicine, International Islamic University Malaysia

${ }^{2}$ Kulliyyah of Medicine, International Islamic University Malaysia

Presenter: Suhaila Binti Nanyan

Introduction: Surgery provides an exceptional chance for smoking cessation and apparently surgeons can play an important role in tobacco control. Tobacco intervention in surgical patients benefited them both in the short-term and longterm health outcome. Unfortunately, little is known about the knowledge, attitudes and practices of Malaysian surgeon regarding peri-operative tobacco smoking interventions which triggers this study. Materials and Methods: A survey of written questionnaires was conducted on medical doctors in the surgical based discipline at the International Islamic University Malaysia Medical Centre. Results: The survey response rate was $100 \%$, and $6.7 \%$ of respondents themselves were current smoker, $23.3 \%$ were former smoker. A high proportion of respondents had accurate perceptions of peri-operative and long-term health risks of smoking. However, most of them also knew how to counsel about smoking or help patients get the help they needed to quit. Majority (93.3\%) of them frequently or almost always asked about smoking status; $56.7 \%$ advised about the health risk of tobacco use; $80.0 \%$ advised patients to stop smoking peri-operatively and $60.0 \%$ advised patients to quit smoking permanently. Compared with non-smokers, smokers were significantly less likely to advice about the health risks of smoking and quitting. Not only that, most of the respondents were willing to learn about peri-operative interventions and spend an extra $5 \mathrm{~min}$ to help patients quit smoking. Conclusions: Majority of the respondents poised adequate knowledge of health risks of smoking, strong perception of responsibilities, and willingness to participate in tobacco control, IIUM Medical Centre doctors actually play a significant role in tobacco control in which could improve peri-operative outcomes and promote long-term health. 